\title{
LncRNA LINC00311 Promotes the
} Proliferation and Differentiation of Osteoclasts in Osteoporotic Rats Throu the Notch Signaling Pathway by Ta: DLL3

\section{DLL3}

Yu Wang ${ }^{a}$ Tian-Bao Luo ${ }^{b}$ Long Liu ${ }^{b}$

aDepartment of Orthopaedics, Peking University First Hospital, Beiji Tsinghua University Second Hospital, Beijing, China

\section{Key Words} Linc00311 DLL3 $\cdot$ Notch signaling patb osis $\cdot$ Proliferation • Differentiation •
Osteoclasts

\section{Abstract}

Background/Aims: Osteopo

bone density. Previous evir nce

treatment tools for the $d$

on the progression of

conducted into the targ

artiment of Neurosurgery,

be highly expre

signaling patk ay rat model $s$ es lis by $\mathrm{DLL}^{3}$

ding

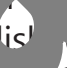
2

a commonly occurring condition marked by a loss of lighted the roles played by microRNAs as potential nt, the influence of long non-coding RNAs (IncRNAs) eopo sis remains largely unclear. Thus, an investigation was nship between LINC00311, which has been reported to steoporosis, and delta-like 3 (DLL3), which is involved in the Notch ection with a series of bioinformatic methods. An osteoporotic re extracted from osteoporotic rats and transfected with the LINC00311-vector, -LIN 11, Notch activator, or a combination of the Notch activator and LINC00311Weste, blotting and RT-qPCR techniques were applied to determine the expression vels C00311, DLL3, Notch1, Notch2, Jagged1, Hes-1 and TRAP in tissues and cells, le cenractivity was detected by MTT assay. The cell cycle as well as the rate of apoptosis was et ted by flow cytometry. The successfully established osteoporotic rats were designated 2. the OVX-siRNA, OVX-LINC00311 and OVX-control groups to observe the effects of ${ }_{1}$ NC00311 on the proliferation and differentiation of osteoclasts. Results: Cells transfected with the LINC00311-vector exhibited increased expression levels of Notch2 and TRPA as well as increased cell activity, while decreased expression levels of DLL3, Notch1, Jagged1 and Hes1 , along with a decreased cell apoptosis rate, were observed. The opposite tendencies of these parameters were observed in the cells treated with shRNA-LINC00311. A key observation 


\section{Cellular Physiology Cell Physiol Biochem 2018;47:2291-2306 \begin{tabular}{l|l} 
DOI: 10.1159/000491539 & $\begin{array}{l}\text { O 2018 The Author(s). Published by S. Karger AG, Basel } \\
\text { www.karger.com/cpb }\end{array}$
\end{tabular} \\ Wang et al.: LINC00311 and DLL3 in Osteoporotic Rats}

was made when the Notch signaling pathway was activated, in that the cell activity was decreased while the rate of apoptosis increased. In comparison with the OVX-control group, the expression levels of LINC00311, Notch2 and TRAP as well as the positive expression rate of TRAP all exhibited reductions, while those of DLL3, Jagged1 and Notch1 were elevated in the OVX-siRNA group. Compared with those in the sham group, in the OVX-control and OV LINC00311 groups, LINC00311 and the expression levels of Notch2 and TRAP were increasec however, decreased levels of DLL3, Jagged1 and Notch1 were noted. Conclusions: Taken together, the key findings of the present study suggest that LINC00311 induces proliferat' and inhibits apoptosis of osteoclasts via the regulation of the Notch signalinc-nathwa inhibiting DLL3 expression, ultimately demonstrating that LINC00311 and its tar may serve as independent factors in cases of osteoporosis.

\section{Introduction}

The hallmark feature of osteoporosis is represented by a syster pairment of bone mass, microarchitecture and strength, with the impairme compan an increased possibility of fragility fractures [1]. Over 200 millio world suffer from osteoporosis [2]. Postmenopausal women represent the $n$ lik, compared with their male counterparts, to be diagnosed with the conditic a a eater prevalence of the disorder strongly correlated with increas; age [3]. Th ost susceptible regions of fragility fracture, as a result of osteoporosis, in the hip, s, and wrist. Osteoporosis continues to place a significant burden not only on ic health but also on the economy [4]. Present treatment approaches for osteoporos iclu. sphosphonates, which are widely considered to be an effective form of treatme 5]. wioactive sphingolipid metabolite sphingosine-1-phosphate (S1P) has be - an essential factor in the regulation of a variety of physiological and patho ys sicar processes including that of osteoporosis [6]. Bone homeostasis is maintained osteoblast and osteoclast activity, with increased acti di loss and potentially causing osteoporosis [2]. Osteoblast differentiation sociatu with the incidence of osteoporosis, with studies implicating long non-codir $\mathrm{Kw}$ ( $\mathrm{A}$ ) as a factor in the condition [7].

LncRNAs are involy an an of biological processes and are understood to be a heterogeneous group of (-cod'ng transcripts longer than $200 \mathrm{nt}$ [8]. LncRNA-DANCR has been reported to ha a po omarker for osteoporosis [9]. Another IncRNA MEG3 has been demonstr uppics osteogenic differentiation; at the same time, lncRNA CCATI/ miR-148a and 01133 have been shown to influence the process of proliferation in cases of teos or 10,11$]$. Studies have highlighted a correlation between the Notch signalin thwa Haju-Cheney syndrome, a disorder that results in osteoporosis [12].Th liferation and differentiation of bone cells from osteoporotic patients could eas to an enhanced Notch signaling pathway; thus, that pathway deserves to tentia ,arget for osteoporosis treatment [13]. Delta-like 3 (DLL3), which at present has identified in mammals, is a divergent ligand and modulator located in the ch synaling pathway, with variations in its expression linked to osteogenic induction 14 15]. Nevertheless, LncRNA and DLL3 have not been investigated from an osteoporosis pective. Thus, the purpose of the present study was to determine the role of lncRNA NC00311 (LINC00311) and DLL3 in osteoporosis and their influence on the cellular processes of osteoclasts through the Notch pathway.

\section{Materials and Methods}

Bioinformatics prediction

The Gene Expression Omnibus (GEO) database (http://www.ncbi.nlm.nih.gov/geo) was explored in order to obtain gene expression data of osteoporosis (GSE7158 and GSE63009) as well as an annotation 


\section{Cellular Physiology Cell Physiol Biochem 2018;47:2291-2306 \begin{tabular}{l|l} 
DOI: 10.1159/000491539 & $\begin{array}{l}\text { O 2018 The Author(s). Published by S. Karger AG, Basel } \\
\text { www.karger.com/cpb }\end{array}$
\end{tabular} \\ Wang et al.: LINC00311 and DLL3 in Osteoporotic Rats}

file. Both microchips were detected by the Affymetrix Human Genome U133 Plus 2.0 Array (Shanghai Sangon Biotechnology Co. Ltd., Shanghai, China). Background correction and normalization of each data chip were processed using Affy package of R software [16]. The linear empirical Bayes model in the limma package was applied to conduct nonspecific filtration of the expression data, while the long non-coding RNA with differential expression were subsequently filtered [17]. MEM is a web-based tool that is largely us for co-expression queries for large collections of gene expression experiments. LncRNA with differentic expression levels were predicted by Multi Experiment Matrix website (MEM, http://biit.cs.ut.ee/mem/) Access to several hundreds of publicly available gene expression datasets of different tissues, diseases conditions was provided by MEM and arranged by microarray platform types and the species [18]. The t gene was analyzed using Kyoto Encyclopedia of Genes and Genomes (KEGG) pathway enr ent an using WebGestalt database (http://www.webgestalt.org) to confirm the major biochemical metabolism and signaling pathways of target gene [19].

\section{Study subjects}

Experiments were performed on healthy 3-month-old non-pregnant females of deformity, trauma or skin infection. The recruited rats weighed approximately by the animal experiment center of Tsinghua University Second Hoc were ho . cages separately, and were granted free access to compound pellet feed, under a $12 \mathrm{~L}$. temperature conditions of $23 \pm 2^{\circ} \mathrm{C}$. A series of intraperitoneal in, ys pentobarbital $(0.35 \mathrm{~mL} / 100 \mathrm{~g})$ were administered to anesthetize rats, and after dis the middle line of their respective abdomens. Rats fo ovariect (OVX) group were sutured by layer after complete removal of the bilateral ovaries, ed by posto ative fasting for $6 \mathrm{~h}$. Surgical sutures were left in. All experiments in the present studv onducted under the approval of the Ethics Committee of Tsinghua University Second Hospital, a ing the principles of animal protection and use. All efforts were made to minimize the suffering o mals estudy.

Cell culture and induction of differentia

Rats with osteoporosis were selecte $3000 \mathrm{U}$ of heparin (H104201, Aladdin, Shanghai, China) intraperitoneall in $75 \%$ ethanol for $10 \mathrm{~min}$. The b washed 3 times with phosphat unie. of the rats was flushed witl $15 \%$ fetal bovine serum (F Peprotech, Rocky Hill.NI. US.

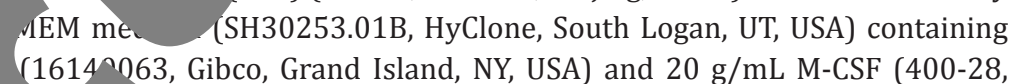
(PBS) (D1040, Solarbio, Beijing, China). The marrow cavity
(Pemu surface was observed to have turned pale, while the cell suspension was prepared by repeand pipetting. The cell suspension was slowly spread on the lymphocyte separating solut 2, Ficoll, Sigma) according to the proportion of 1: 1, centrifuged at $3000 \mathrm{r} /$ min for $5 \mathrm{mi}$ vith a ua wume of serum-free $\alpha$-MEM added to the middle layer of the mononuclear cells, and centr at 1 ain for $5 \mathrm{~min}$. The supernatant was discarded, and the cells were suspended with $15 \%$ FBS $\quad \mathrm{g} / \mathrm{mL}$ M-CS. The cell density was adjusted to $1 \times 10^{4} \mathrm{cell} / \mathrm{mL}$, followed by inoculation in a 25 cure $\quad 37^{\circ} \mathrm{C}$ in $5 \% \mathrm{CO}_{2}$ under saturated humidity conditions. Following $2-3 \mathrm{~h}$ of incubation, the erent $a_{1}$ s were collected. The cells were then suspended with $\alpha$-MEM medium comprising $15 \%$ M-CSF, 50 ng/mL recombinant human RANK ligand (RANKL) (ab69517, Abcam, Cambridge, USA), 10 mmol N-2-hydroxyethylpiperazine-N'-2-ethanesulfonic acid (HEPES) (15630080, Gibco), 100 $1 \mathrm{r}$ - penicillin and $100 \mu \mathrm{g} / \mathrm{mL}$ streptomycin (SV30010, HyClone). Cell density was adjusted to $1 \times 10^{6}$ cell/ nd the cells were then seeded into six-well plates $(3 \mathrm{~mL} /$ well).

\section{Reverse transcription quantitative polymerase chain reaction (RT-qPCR)}

Total RNA was extracted from the tissues and cells using a Trizol kit (15596026, Life Technologies, Gaithersburg, MD, USA). The cDNA template was synthesized using a reverse transcription kit (18091050, Invitrogen, Carlsbad, CA, USA). After the reaction, the cDNA was either placed on ice or stored at $-20^{\circ} \mathrm{C}$. Realtime amplification was performed using an ABI7300 PCR instrument. The reaction system was composed of $1 \mu \mathrm{L}$ of upstream and downstream primer (concentration of $10 \mu \mathrm{mol} / \mathrm{L}$ each), $1 \mu \mathrm{L}$ of cDNA template, $10 \mu \mathrm{L}$ of $2 \times$ SYBR Green qPCR Mix, and $7 \mu \mathrm{L}$ of $\mathrm{ddH}_{2} \mathrm{O}$. The reaction conditions were at $95^{\circ} \mathrm{C}$ for $3 \mathrm{~min}$, at $95^{\circ} \mathrm{C}$ for $12 \mathrm{~s}$ and at $62^{\circ} \mathrm{C}$ for $40 \mathrm{~s}$ with 40 cycles. The $2^{-\Delta \Delta C t}$ was used to highlight the relationship of the target gene 
Wang et al.: LINC00311 and DLL3 in Osteoporotic Rats

expression between the experiment and control groups. $\Delta \Delta \mathrm{Ct}=\Delta \mathrm{Ct}_{\text {ovariectomy }}-\Delta \mathrm{Ct}_{\text {normal }}, \Delta \mathrm{Ct}=\mathrm{Ct}_{\mathrm{RNA}-} \mathrm{Ct}$ internal reference RNA. Each experiment was repeated three times in order to obtain the average value. $\beta$-actin was regarded as the internal reference [20] (Table 1).

\section{Western blotting}

The total protein of both tissues and cells was extracted by means of radioimmunoprecipitation (RIPA) assay buffer containing phenylmethane sulfonyl fluoride (PMSF). The Bradford method was applied in order to determine the concentration of total protein. After $10 \%$ sodium dodecyl sulfate-polyacrylamide gel electrophoresis (SDSPAGE), the separated protein was transferred onto polyvinylidene fluoride (PVDF) membranes (LC2005, Invitrogen, CA, USA), sealed by Trisbuffered saline and Tris-buffered saline with Tween- 20 h. $\beta$-Actin, which was regarded as the internal reference, was incubate rabbit anti-DLL3 (\#2483, CST, Beverly, MA, USA) at 000 dilution, USA) at 1:10000 dilution, Notch2 (\#4530, CST, Beverly, Invitrogen) at 1: 1000 dilution, Hes-1 (PA5-23283, Invit. phosphatase (TRAP) (ab126775, Abcam) at 1: 1000 CA, USA) antibody at 1: 2000 dilution. Next, horsera antibody (ab150077, Abcam) was used for hv ${ }^{-d_{i}}$ recording. After scanning, the Gel-Pro Analy to analyze the gray values of protein bands.
Table 1. Prime sequence for RT-qPCR. Note: RTqPCR, reverse transcription quantitative polymerase chain reaction; $\mathrm{F}$, forward; $\mathrm{R}$, reverse; DLL3, deltalike 3; Hes-1, hairy and enhancer of split-1; TRAP, tartrate-resistant acid phosphatase

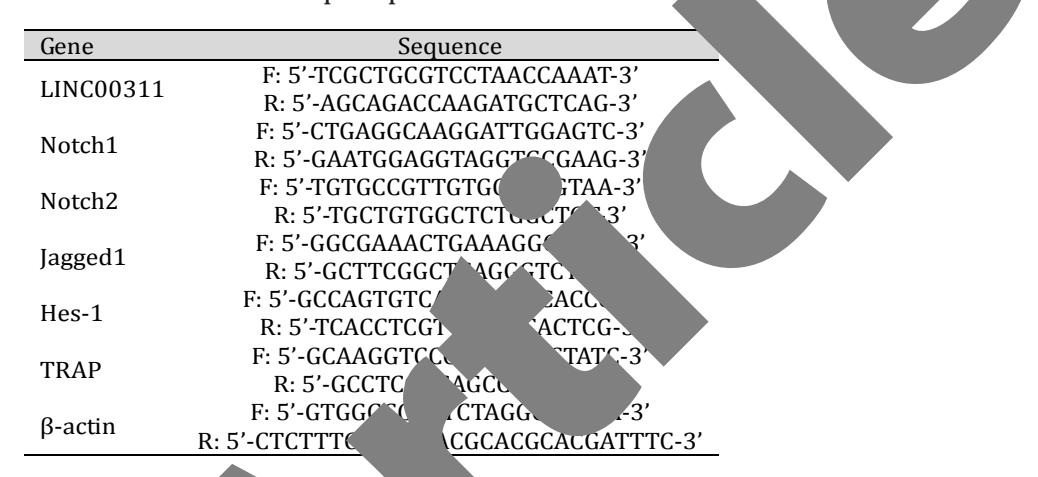

\section{Cell transfection}

The osteoclasts were ino llata $24 \mathrm{~h}$ prior to cell transfection. Upon reaching $50 \%$ confluence, the cells were sfected cordance with the instructions of the Lipofectamine 2000 (11668019, Thermo Fisher tific, "'altham, MA, USA). Following transfection, the medium was changed after $6 \mathrm{~h}$ had elapsed The ce en collected for subsequent experiments after $48 \mathrm{~h}$. The cells were assigned into the 1-vecor group (transfected with LINC00311 plasmid), the blank group (cells without transfe ative control (NC) group (transfected with empty plasmid), the shRNALINC00311 up (t sfe with the LINC00311 silencing sequence, the most efficient silent sequences were scr fron A-LINC00311-1, shRNA-LINC00311-2, and shRNA-LINC00311-3), the Notch $a^{\text {-tivator }}$ Notch signaling pathway activator rh-NF- $\kappa B$ at $1 \mathrm{gsu} / \mathrm{mL}$ was added to the medium without ction, he Notch activator + LINC00311-vector group (Notch signaling pathway activator rh-NFsu/mL as added to the medium for the transfection of the LINC00311 plasmid) (Table 2). min, and then washed with double-distilled water three times. The number of osteoclasts were observed and counted under a microscope (DM1000, Leica, Wetzlar, Germany), and cells with 3 nuclei or more were considered to be osteoclasts, followed by TRAP-positive staining. Two slices were obtained from each rat and observed under a $10 \times 20$-fold light microscope. Five microscopic visual fields $(\times 100)$ were randomly sampled from each slice. The number of osteoclasts in each field was counted, and the mean number of osteoclasts was subsequently calculated. 
Table 2. Transfection sequence

\begin{abstract}
\begin{tabular}{ll}
\hline Name & Sequence \\
\hline shRNA-LINC00311-1 & 5'-TGCTGTTGACAGTGAGCGCCCTCGCTGCGTCCTAACCAAATAGTGAAGCCACAGATGTATTTGGTTAGGACGCAGCGAGGATGCCTACTGCCTCGGA-3'
\end{tabular} $\begin{array}{ll}\text { ShRNA-LINC00311-1 } & \text { 5'-TGCTGTTGACAGTGAGCGCCCTCGCTGCGTCCTAACCAAATAGTGAAGCCACAGATGTATTTGGTTAGGACGCAGCGAGGATGCCTACTGCCTCGGA-3' } \\ \text { shRNA-LINC00311-2 } & \text { 5'-TGCTGTTGACAGTGAGCGACCTAACTCAGGCAGAGTAGTTTAGTGAAGCCACAGATGTAAACTACTCTGCCTGAGTTAGGCTGCCTACTGCCTCGGA-3' }\end{array}$ 5hRNA-LINC00311-3
5'-CCGGGTCCTAACCAAATGCTGGACTCTCGAGAGTCCAGCATTTGGTTAGGACTTTTTTG-3'
\end{abstract}

\title{
MTT assay
}

After transfection, the density of single cell suspension was adjusted to $5 \times 10^{6} \mathrm{cell} / \mathrm{mL}$, and the cells were seeded into 96-well plates in each group after cell adherence. Three wells were randomly seler from each group; at the $12^{\text {th }}, 24^{\text {th }}$ and $48^{\text {th }} \mathrm{h}$ marks, $20 \mu \mathrm{L}$ of $5 \mathrm{mg} / \mathrm{mL}$ MTT $(\mathrm{M} 2128$, Sigmal was add those wells for an additional $4 \mathrm{~h}$ of culturing, followed by removal of the culture medium. $\mathrm{Di}$ (DMSO, $150 \mu \mathrm{L}$; D5879-100ML, Sigma) was then added to each well. The plate was placed void of light and vortexed for $10 \mathrm{~min}$ with the absorbance value measured at $570 \mathrm{~nm}$. 7 e repeated 3 times.

\section{5-ethynyl-2'-deoxyuridine (EdU) cell proliferation assay}

EdU was used to measure cell viability, which consisted of a chemical meth detection of DNA synthesis in vivo. Cells in the logarithmic growth $p^{\prime}$ were con and adjusted to a density of $5 \times 10 / \mathrm{mL}$ and seeded into a 12-well plate. Upon wall a cells transfected and then cultured for $72 \mathrm{~h}$. Next, $300 \mu \mathrm{L}$ of EdU medium $(50 \mu \mathrm{M})$ was ac to $\mathrm{l}$ for incubation for $2 \mathrm{~h}$, with the medium discarded. The cells were then washed twice with $\mathrm{P}_{\mathrm{L}}$ po ashing). Afterward, 50 $\mu \mathrm{L}$ of fixation fluid (PBS $+4 \%$ polyoxymethylene) was colls to the cell and incubated at room temperature for $30 \mathrm{~min}$, with the fixation allowed to ru $\quad f$ ter the add of $50 \mu \mathrm{L}$ of glycine $(2 \mathrm{mg} / \mathrm{mL})$ in each well, the cells were discolored, placed on the shak $\quad l e$ and incubated for 5 min, followed by the removal of the glycine. Next, $100 \mu \mathrm{L}$ of $1 \mathrm{X}$ Apollo® wa aec cells, discolored, placed on the shaking table and incubated at room temperature for $30 \mathrm{~min} \mathrm{u}$ darlions, with the reaction allowed to dip off. Finally, the cells were added with $100 \mu \mathrm{L}$ of metr $\quad 0.5 \%$ TritonX-100), discolored, placed on the shaking table and rinsed $2-3$ times $(10 \quad \mathrm{P}$ sing, with the penetrant discarded. Flow cytometry was used to detect the fluorescence intensi

Flow cytometry

After $48 \mathrm{~h}$ of transfection removal, and suspended witl $\mathrm{mL}$, and $1 \mathrm{~mL}$ of precooling centrifuged, the ethanol was supernatant; next a water bath for ni mixing. After voidir gh
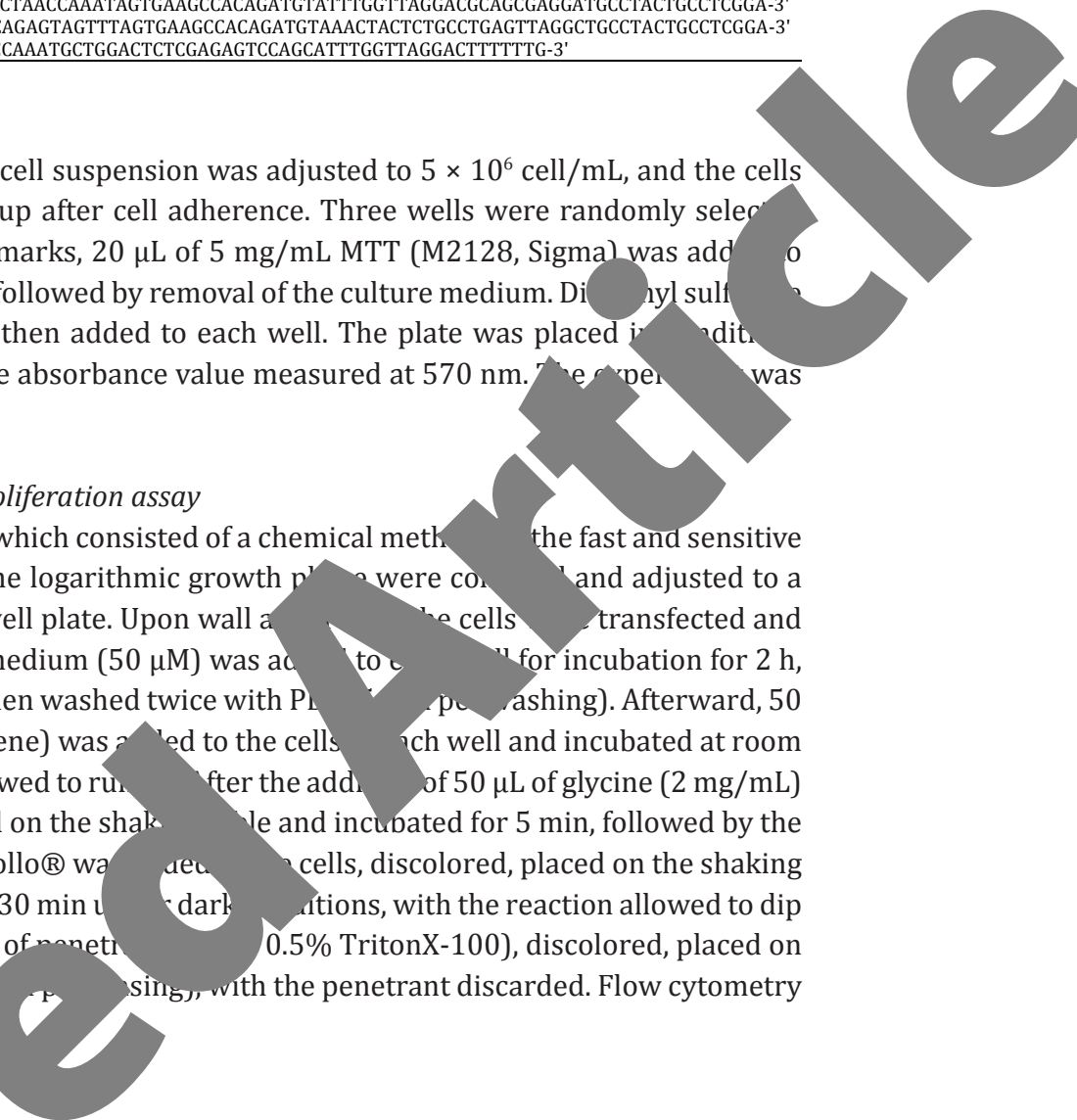
applied to $r$ rd the orescence at a wavelength of $488 \mathrm{~nm}$ for cell cycle access purposes. $400 \mu \mathrm{L}$ of propidium iodide (PI) (P4170, Sigma) was added for staining and washed three times with PBS, centrifuged for supernatant o. The co ration of the cells was adjusted to approximately $1 \times 10^{5}$ cell/ etharol was added to fix the cells for $1 \mathrm{~h}$ at $4^{\circ} \mathrm{C}$, after which the cells were and the cells were washed with PBS twice in order to discard the was added while avoiding light exposure, and the cells were heated in

Aft
DTA of transfection, the cells were treated with trypsin-free ethylenediaminetetraacetic trifuge, he supernatant was then removed, followed by three cold PBS washes. Based on the instr. an annexin-V-FITC apoptosis detection kit (K201-100, Biovision, Milpitas, CA, USA), annexin-

TC, - and HEPES buffer were mixed at a proportion of 1: 2: 50 for the annexin-V-FITC/PI dye. Cells

a) $y^{4}+e_{\text {d }} 1 \times 10^{6}$ were suspended with $100 \mu \mathrm{L}$ each of the dye, vibrated and mixed, followed by incubation m temperature for $15 \mathrm{~min}$. Subsequently, $1 \mathrm{~mL}$ of HEPES buffer was added, vibrated and mixed. FITC a PI fluorescence were detected by $525 \mathrm{~nm}$ and $620 \mathrm{~nm}$ band filters at $488 \mathrm{~nm}$ wavelength, and apoptosis was detected accordingly.

\section{In vivo identification experiment}

Twenty-four rats were randomly selected as the sham group, while seventy-two rats were placed into the OVX group. All rats were anesthetized by means of intraperitoneal injection with $0.8 \%$ sodium pentobarbital $(0.35 \mathrm{~mL} / 100 \mathrm{~g})$. Following disinfection, an incision was made along the middle line of the abdomen. The rats in the OVX group were sutured by layer after complete removal of bilateral ovaries and undergoing a $6 \mathrm{~h}$ period of postoperative fasting. Six hours later, the rats were granted free access 


\section{Cellular Physiology Cell Physiol Biochem 2018;47:2291-2306 \begin{tabular}{l|l} 
DOI: 10.1159/000491539 & $\begin{array}{l}\text { O 2018 The Author(s). Published by S. Karger AG, Basel } \\
\text { www.karger.com/cpb }\end{array}$
\end{tabular} \\ Wang et al.: LINC00311 and DLL3 in Osteoporotic Rats}

to water. The surgical sutures were left in. The sham group underwent a sham surgery without ovary removal. The rats were then fed in a well-ventilated environment at room temperature with natural light or the specific pathogen-free (SPF) condition. Then, 24 rats were randomly selected from the OVX group and intraperitoneally injected with siRNA or LINC00311 separately and served as the OVX-siRNA group and the OVX-LINC00311 group, respectively, with the remaining rats as the OVX-control group. Dual ener X-ray absorptiometry (DEXA, Hologic QDR24500A, Waltham, MA, USA) was applied to access the bone mas density (BMD) after 3 months had elapsed.

\section{Hematoxylin-eosin (HE) staining}

Decalcification of bone tissue process was conducted according to the following: the ri subsequently immersed in a mixture of $330 \mathrm{~mL}$ of formic acid, $660 \mathrm{~mL}$ of $10 \%$ formalin, hydrochloric acid for decalcification, with the mixture changed at frequent intervals were extracted and washed with flowing water for $12 \mathrm{~h}$ until they could be easily pun syringes.

To slice bone tissue, a rotary microtome (RM2245, Leica) was used. The th follows: the femurs were extracted, washed using running water for $30 \mathrm{~min}$, imm. 95\% ethanol II for 30 min each, and immersed in absolute ethanol $/ \mathrm{h}$, absolu absolute ethanol III for $1 \mathrm{~h}$. The slices were then sequentially imr ad III, (X820585$500 \mathrm{~mL}$, HongZhe Biological Technology Limited Company, Anhui, C for nd $0.5 \mathrm{~h}$, respectively. Next, the samples were treated in paraffin I, II and III for $0.5 \mathrm{~h}, 1 \mathrm{~h}$ an res retively, embedded with embedding machines and sliced by ultra-thin semi-a atic microto The distal femurs were sliced into $4 \mu \mathrm{m}$ sequential slices and attached to an anti-slip pr roasting o $\mathrm{C}$.

\section{Statistical analysis}

SPSS 21.0 software (IBM Corp., Armonk, NY, are presented as the mean \pm standard devi
(SD). Comparisons between the two group examined using the $t$-test, while com among more than two groups w one-way analysis of variance (AN were considered to be signific than 0.05 .

\section{Results}

LINCO 11 i: led for this study

The ysis GSE7158, in regard ts ostec sis, revealed that LINC00311

iigh, pressed in osteoporosis

05) (1. . 1A). The analysis of chip howed that after being treated bisprosphonate, the expression of / $>0311$ in osteoclasts was reduced so than in those that were not treated g. 1B), further confirming the high expression of LINC00311 in osteoclasts. Hence, LINC00311 was selected for further study.

\section{DLL3 is a target gene of LINC00311}

The MEM website was employed for the prediction of the target gene of IncRNA, the results of which revealed that DLL3 was

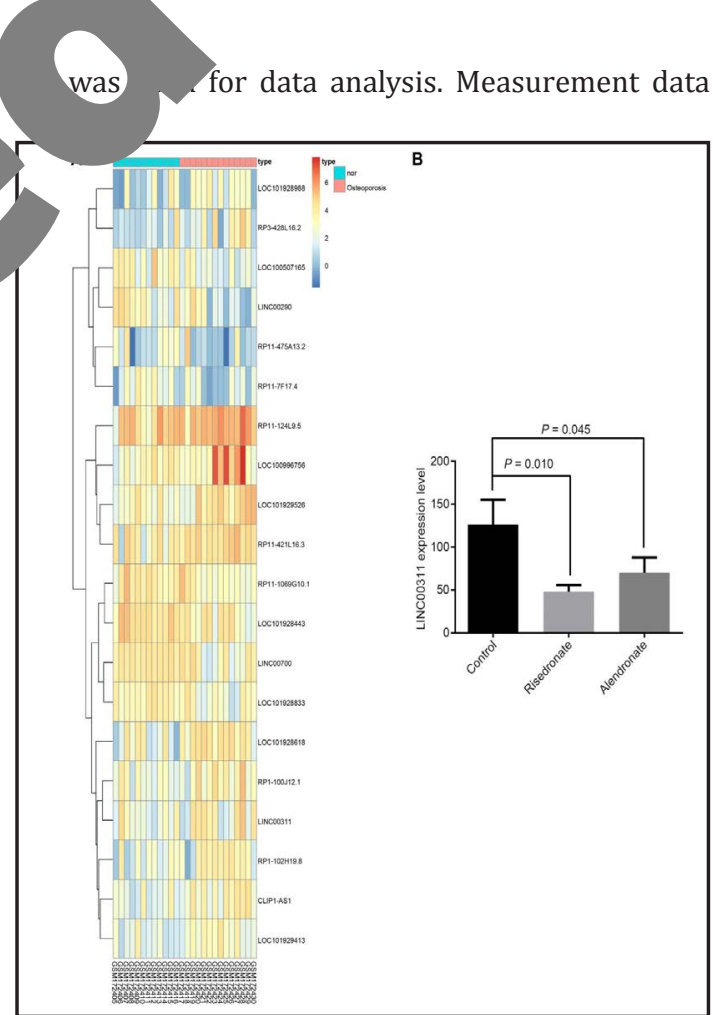

Fig. 1. LINC00311 expresses at a high level in osteoclasts during osteoporosis (A: GSE7158; B: GSE63009) Note: $\mathrm{N}=3$. 

Cellular Physiology Cell Physiol Biochem 2018;47:2291-2306 \begin{tabular}{c|c|c|} 
DOI: 10.1159/000491539 & $\begin{array}{l}\text { O } 2018 \text { The Author(s). Published by S. Karger AG, Basel } \\
\text { www.karger.com/cpb }\end{array}$
\end{tabular}
Wang et al.: LINC00311 and DLL3 in Osteoporotic Rats

a target gene of LINC00311 (Fig. 2), which could also regulate the Notch signaling pathway (Table 3).

\section{LINC00311-shRNA1 is prepared for further experiment}

Osteoclasts were separately transfected with shRNA-control and LINC00311-shRNA LINC00311-shRNA-2 and LINC00311-shRNA-3. After a 48-h transfection, RT-qPCR wa applied in order to detect the expression of LINC00311. As shown in Fig. 3, in comparison with that in the shRNA-control, LINC00311 was expressed at a lower level in LINC003 shRNA-1, LINC00311-shRNA-2 and LINC00311-shRNA-3, where LINC00211-shR showed the lowest expression of LINC00311. Thus, LINC00311-shRNA1 wa electe the following experiment.

\section{LINC00311 increases TRAP-positive osteoclasts in osteoporotic rats}

TRAP staining was applied in order to observe the pathological cha The results of TRAP staining are illustrated in Fig. 4. After the induction a number of cells exhibited an increased size with irregular shapes filamentous, with a greater number of nuclei observed (ny $>3$ ), wh to be osteoclasts. There was no difference observed rega is inber TRAP-positive osteoclasts between the blank and NC groups $(p>0.05)$. $C$ par that of the NC and blank groups, the number of TRAP-positive osteoclasts wa dicantly increased in the LINC00311-vector group $(p<0.05)$. In the shR UINC00311 up and the Notch activator group, the number of TRAPpositive osteoclasts was significantly decreased $(p<0.05)$. No significant difference regarding the number of TRAPpositive osteoclasts in the LINC00311-vector + Notch activator group was detected $(p>0.05)$. The findings suggested LINC00311 overexpres might increase the num. of TRAP-positiy in osteoporot:

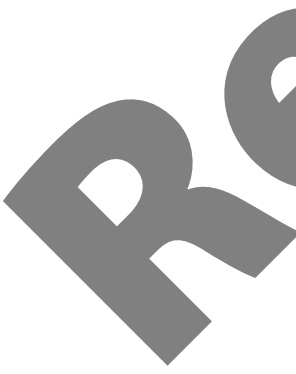

\section{MIN 11 and TRAP RNA ssion levels ile des, ending DLL3, Jagged1, and Hes-1 in osteoporotic ats RT-qPCR was applied order to detect the} mRNA expression levels of LINC00311, DLL3, Notch1, Notch2, Jagged1, and Hes1. Between the blank and NC groups, no significant difference was observed regarding the expression levels of LINC00311,

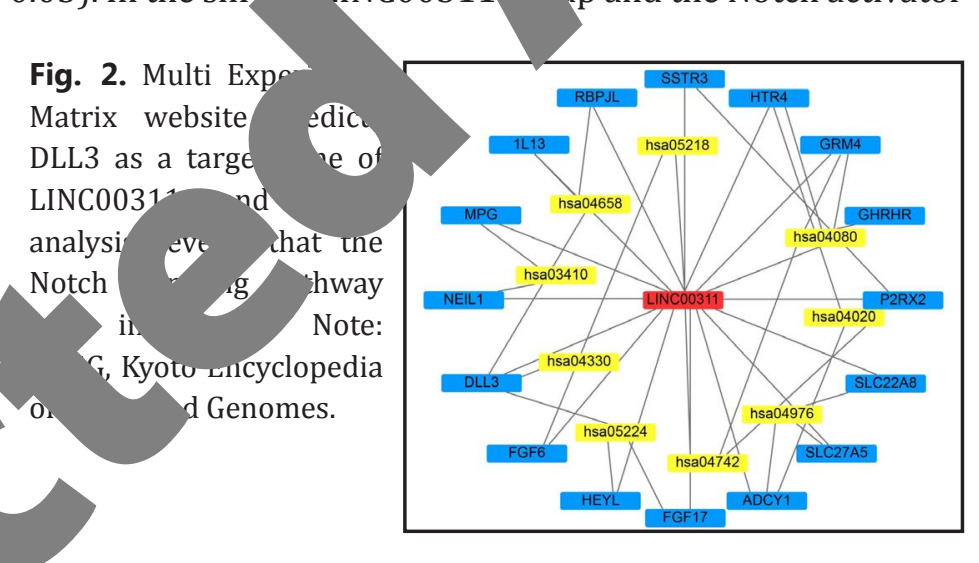

Table 3. Enrichment analysis of KEGG signaling pathways of the target gene of LINC00311. Note: KEGG, Kyoto Encyclopedia of Genes and Genomes; DLL3, delta-like 3; FGF6, fibroblast growth factor 6; HEYL, Hes-related family bHLH transcription factor with YRPW motif-like; ADCY1, adenylate cyclase 1; SLC27A5, solute carrier family 27 member 5; P2RX2, purinergic receptor P2X 2; GHRHR, growth hormonereleasing hormone receptor; GRM4, glutamate metabotropic receptor 4; HTR, 4,5-hydroxytryptamine receptor 4; SSTR3, somatostatin receptor 3; RBPJL, recombination signal binding protein for immunoglobulin kappa J region-like; IL13, interleukin 13; MPG, N-methylpurine DNA glycosylase

\begin{tabular}{llc}
\hline Pathway & P value & Gene \\
\hline Breast cancer & 0.0039 & DLL3;FGF6;HEYL;FGF17 \\
Bile secretion & 0.0040 & ADCY1;SLC27A5;SLC22A8 \\
Neuroactive ligand-receptor interaction & 0.0072 & P2RX2;GHRHR;GRM4;HTR4;SSTR3 \\
Th1 and Th2 cell differentiation & 0.0074 & DLL3;RBPJL;IL13 \\
Base excision repair & 0.0103 & MPG;NEIL1 \\
Notch signaling pathway & 0.0187 & DLL3 \\
Taste transduction & 0.0423 & P2RX2;GRM4 \\
Melanoma & 0.0423 & FGF6;FGF17 \\
Calcium signaling pathway & 0.0478 & ADCY1;P2RX2;HTR4 \\
\hline
\end{tabular}


mRNA expression levels of Notch2 and DLL3 or those of the related genes in the Notch signaling pathway (all $p<0.05$ ). Compared with those of the blank and NC groups, increased expression levels of LINC00311, Notch2 and TRAP were detected in the LINC00311-vector group (both $p<0.05$ ), while the other mRNA expression levels exhibited marked decreases (all $p<0.05$ ). The expression levels of LINC00311 and TRAP were decreased in the shRN LINC00311 group, while the expression levels of the other genes all exhibited distin increases (all $p<0.05$ ). In the Notch activator group, the mRNA expression levels of Notch1 Notch2, Jagged1 and Hes-1 were elevated, although no significant difference in relatior the expression levels of LINC00311 and DLL3 was observed, while the mRN^ expres of TRAP decreased (all $p<0.05$ ). In the LINC00311-vector + Notch activat group, expression levels of LINC00311 and Notch2 were notably increased, while the ex DLL3 was significantly decreased $(p<0.05)$. No significant difference wa to the expression levels of TRAP, Notch1, Notch2, Jagged1 and Hes-1 (all, 05) (h). In osteoclasts, LINC00311 overexpression was shown to increase Notcl o.A expression levels while lowering the mRNA expression levels of Dr Noto otch2, Jagged1, and Hes-1.

LINC00311 elevates Notch2 and TRAP protein expr Notch1, Jagged1, and Hes-1 in osteoporotic rats

Western blotting methods were conducted in order to levels of LINC00311, DLL3, Notch1, Notch2, Jae 11, and Hesdifference between the blank group and the $\mathrm{NC}$ was dete in relation to the protein expression levels of LINC00311 and DLL3 or lated genes in the Notch signaling pathway (all $p>0.05$ ). Compared with those o blo nd NC groups, expression levels of the TRAP protein in the LINC00311-vector gro vere afficantly increased, while those of the other proteins were notably decrea (all, 6). The expression of Notch2 and TRAP $p$ cer the SnRNALINC00311 group was significantly while the expression levels of the oth gnificantly increased (all $p<0.05$ ). $\mathrm{N}$ ificanı uifference was observed in regard to the ores activator group $(p>0$, while expression levels of Notch1, Notch2, Ja 1 a $r^{\wedge}$ Hes-1 proteins were significantly increacod, a ed by notably decreased expression leve' TRAr protein (all $p<0.05$ ). Notch2 expression le s creased and DLL3 expression levels sign sant a rased in the LINC00311-vector + Notch for g $(p<0.05)$, while Notch1, Notch2, I'rged1, 1 and TRAP expression levels had no kablo vrences (all $p>0.05$ ) (Fig. 6). Based on ained esults, we concluded that in osteoclasts,

Fig. 3. LINC00311-shRNA1 is selected for further experiments. Note: $\mathrm{N}=3$; the comparison was analyzed using an ANOVA.

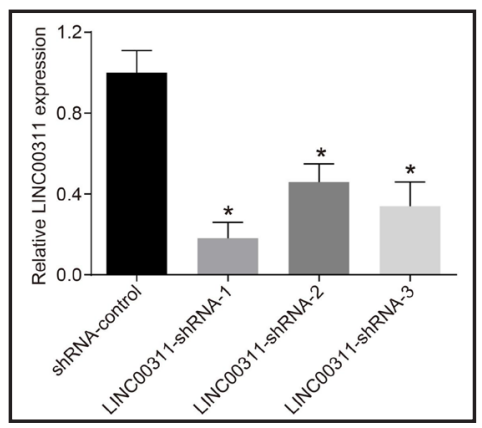

4. -RAP staining results dije that LINC00311 increases leoporotic rats $(\times 200)$. Note: $\mathrm{N}$ = 5; the comparison was analyzed using an ANOVA; A, TRAP staining of bone tissues in each group; $\mathrm{B}$, diagram of TRAP-positive cell number in each group; ${ }^{*}, \mathrm{p}<0.05$ compared with the NC and blank groups; ANOVA, one-way analysis

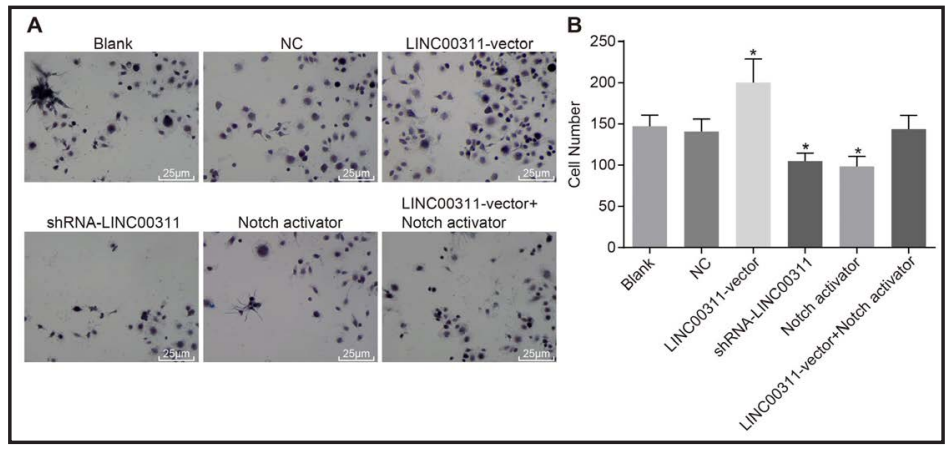
of variance. 
Fig. 5. RT-qPCR suggests that LINC00311 elevates Notch2 and TRAP mRNA expression levels while descending DLL3, Notch1, Jagged1, and Hes-1 in osteoporotic rats. Note: $\mathrm{N}=3$; the comparison was analyzed using an ANOVA; ${ }^{*}, \mathrm{p}<0.05$ compared with the NC and blank groups; DLL3, delta-like 3; Hes-1, hairy and enhancer of split-1; TRAP, tartrate-resistant acid phosphatase.

Fig. 6. Western blot analysis indicates that LINC00311 increases Notch2 and TRAP protein expression levels while lowering DLL3, Notch1, Jagged1, and Hes-1 in osteoporotic rats. Note: $\mathrm{N}=$ 3 ; the comparison was analyzed using an ANOVA; A, protein bands in each group, B, protein expression levels in each group; *, p<0.05 compared with the NC group and the blank group; ANOVA, one-way analysis of variance; DLL3, delta-like 3; Hes-1, hairy and enhancer of split-1; TRAP, tartrate-resistant acid phosphatase; NC, negative control.

LINC00311 overexpression could increase No reducing the protein expression levels of
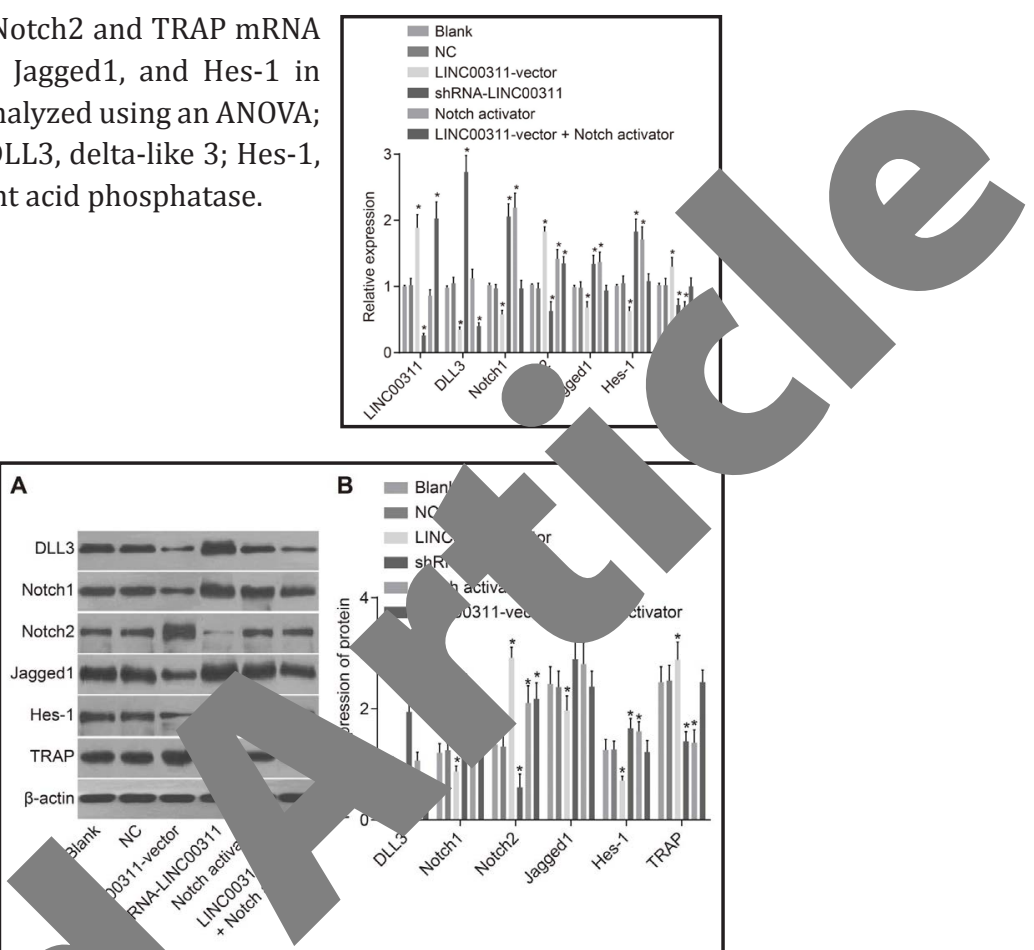

\section{LINC00311 promotes the prolifer}

The MTT assay was emr demonstrated that there was between the NC and blank oup. the cell proliferation act in the NA-LINC00311 group and the Notch activator group was significantly reduc while the proliferation activity in the LINC00311-vector group was markedly increased activity in the Novos11 + Notch activator group was observed ( $p>0.05)$ (Fig. 7). The afore ne nults demonstrated that LINC00311 overexpression could be attributed the lif mion of osteoclasts.

1 promotes the proliferation of osteoclasts in osteoporotic rats

1 Ea ay was applied in order to measure osteoclast proliferation, the results h are alustrated in Fig. 8. No significant difference was observed in regard to broh between the NC and blank group $(p>0.05)$. Compared with those of the blank $\mathrm{NC}$ groups, the fluorescence intensity and proliferation in the shRNA-LINC00311 and $0^{+/} \mathrm{h}$ activator groups were significantly reduced (both $p<0.05$ ); the fluorescence intensity proliferation in the LINC00311-vector group were significantly elevated (both $p<0.05$ ); id cell proliferation in the LINC00311-vector + Notch activator group showed no notable difference $(p>0.05)$. The above results indicated that LINC00311 overexpression might be attributed to the proliferation of osteoclasts.

LINC00311 accelerates osteoclast growth and inhibits apoptosis in osteoporotic rats

Flow cytometry was performed to determine cell cycle and apoptosis. PI staining results revealed that there was no significant difference regarding cell cycle distribution between the blank and NC groups $(p>0.05)$. Compared with that of the blank and NC groups, the proportion of cells at the G1 phase was markedly increased, while the proportion of cells

\section{KARGER}


Fig. 7. LINC00311 promotes the osteoclast proliferation in osteoporotic rats detected by MTT assay. Note: $\mathrm{N}=3$; the comparison was analyzed using an ANOVA; *, p<0.05 compared with the NC group and the blank group; MTT, 3-[4,5-dimethylthiazol-2-yl]-2,5 diphenyl tetrazolium bromide; OD, optical density; NC: negative control; DLL3: delta-like 3; Hes-1: hairy and enhancer of split-1; TRAP: tartrateresistant acid phosphatase.

at the S and G2 phases was significantly decreased in the shRNA-LINC00311 group and Notch activator group (all $p<0.05$ ). The proportion of cells at the G1 phase in the LINC00311-vector group was notably reduced, while the proportion of cells at the S1 and G2 phases were significantly increased (all $p<0.05$ ). No significant difference regarding the percentage of cells at the G1, S and G2 phases in the LINC00311-vector + Notch activator group was detected (all $p>0.05$ ) (Fig. 9).

Annexin V/PI double-staining results indicated that compared with that of blank group and the NC group, the apo rate of the LINC00311-vector grou significantly decreased, whi apoptosis in the shRNA-LIN and the Notch activator gr $\mathrm{p} n$ increased (all $p<0.0$ ihere $r$ ra significant difference $d$ ted in regard to the rate of apoptosic rate ,C00311vector + shRNA $\quad 31$ group $(p>0.05)$

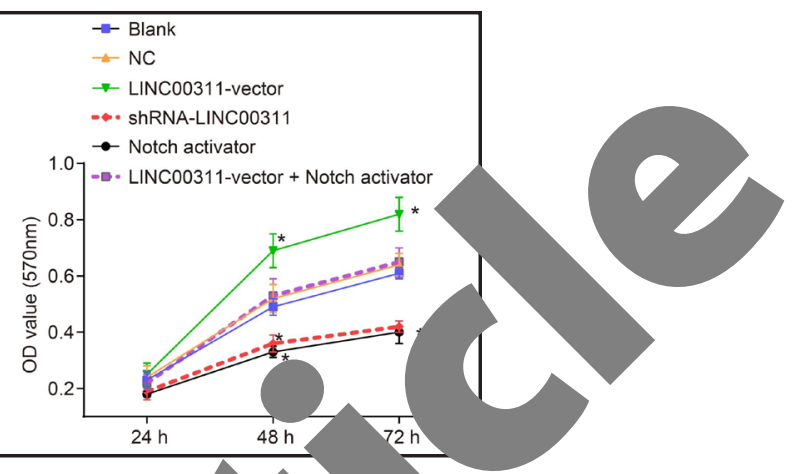
(Fig. 10). The oy gs indicated that LINC0031 ver re night promote the proliferation of osteoclasts while hindering the pros fapo s. i. EVX-LINC00311 group, while no notable reductions were detected in the OVX-siRNA oroup.

\section{Pathological changes of bone tissues in the sham and OVX groups are observed}

HE staining was used to observe pathological changes of bone tissues in the sham and OVX groups. As shown in Fig. 12, the rats in the sham group were discovered to have uniform, robust, plump, reticulate, continuous, dense, regular, rich, brown and well-formed trabecular bone of the cancellous bone area. The bone marrow cavity was small with abundant marrow cells within the cavity with a scarce amount of fat droplets. Compared with that of the sham group, the trabecular bone in the cancellous bone area of the rats in the OVX group was

\section{KARGER}


Fig. 9. PI staining results indicates that LINC00311 accelerates osteoclast cell cycle progression in osteoporotic rats. Note: $\mathrm{N}=3$; the comparison was analyzed using an ANOVA; A, flow cytometry results for cell cycle; B, comparison of cell cycle distribution; *, $\mathrm{p}<0.05$ compared with the NC group and the blank group; $\mathrm{NC}$, negative control; DLL3, delta-like 3; Hes1 , hairy and enhancer of split-1; TRAP, tartrate- resistant acid phosphatase.

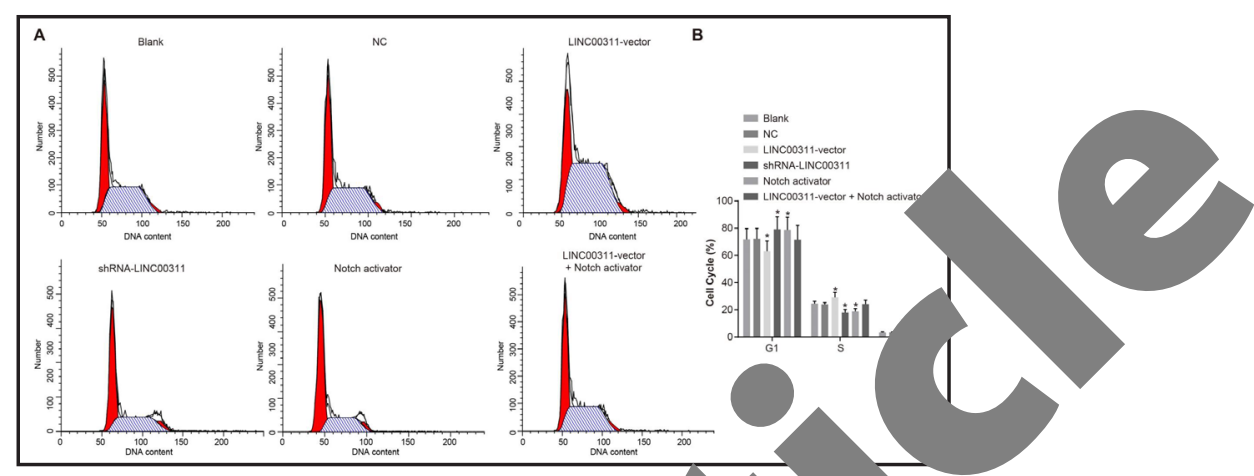

Fig. 10. Annexin V/PI double staining reveals that LINC00311 inhibits osteoclast apoptosis in osteoporotic rats. Note: $\mathrm{N}=3$; comparison analyzed using an ANOVA; A, flow cytometry results for cell apoptosis; B, comparison of cell apoptosis rate; *, p<0.05 compared with the NC group and the blank group; NC, negative control; DLL3, delta-like 3; Hes1 , hairy and enhancer of split-1; TRAP, tartrate- resistant acid phosphatase.

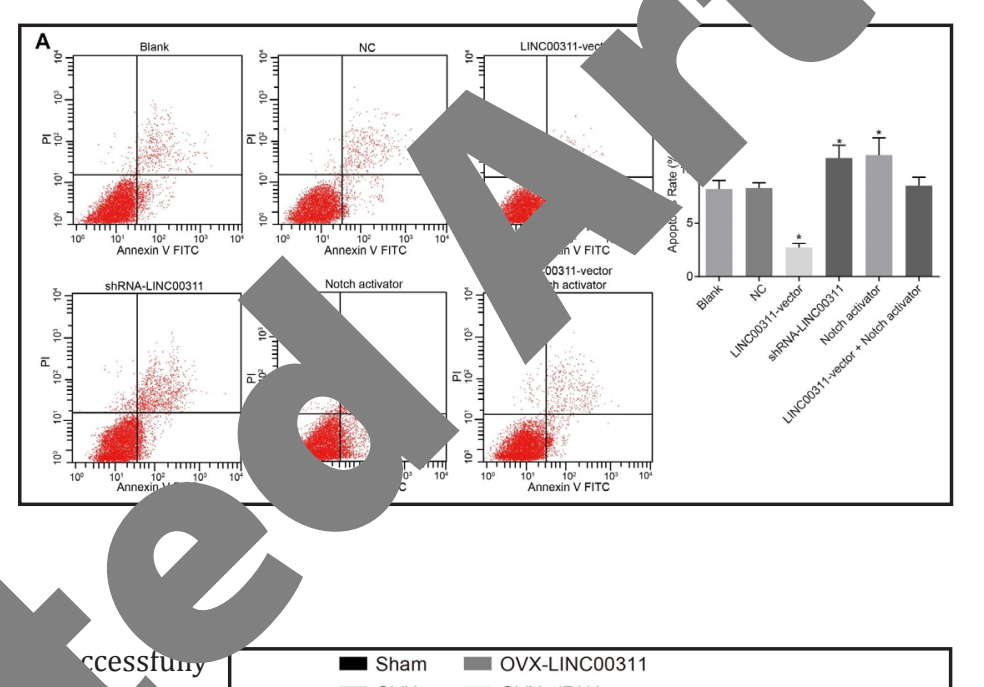

Fig. 11. Osteoporotic rat mode established. Note: $\mathrm{N}=24$; $t$ analyzed using an ANOVA. with the sham group; L4, the fifth lumbar; BMD bon ovariectomy.
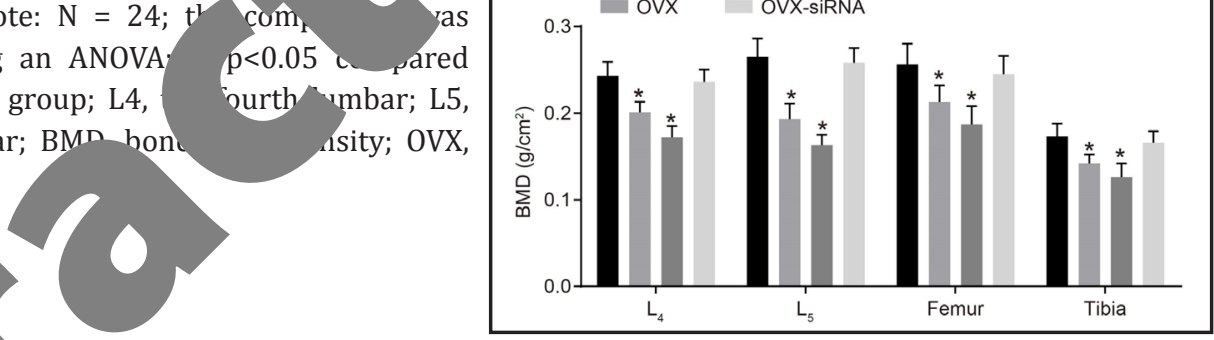

cantly aced, sparse, irregular, and partial fractured; the connectivity between the $t$. vity decreased hematopoietic cells and increased fat droplets. Compared to that in sham group, in the OVX-siRNA group, the trabecular bone in the cancellous bone area of at xhibited a slight decrease and was sparse, while the bone marrow cavity was partially rged with a decreased amount of fat droplets.

\section{LINC00311 increases TRAP positive osteoclasts in osteoporotic rats}

To determine the number of positive cells in the osteoporotic rats, TRAP staining was employed. The cells were regarded as osteoclasts in the event that the number of nuclei was greater than 3 , as subsequently determined to be positive by TRAP staining. The TRAP staining results indicated that the number of positive cells in the osteoporotic bone tissue in the OVX group $(5.36 \pm 0.93)$ and the OVX-LINC00311 group ( $8.62 \pm 0.87)$ was much higher than that in the sham group $(2.35 \pm 0.79)(p<0.05)$. The number of positive cells in osteoporotic 
bone tissue in the OVX-siRNA group was $2.58 \pm 1.12$, which showed no significant difference when compared with that of the sham group (Fig. 13). The results suggested that LINC00311 might increase the amount of TRAP-positive bone tissues in osteoporotic rats.

LINC00311 elevates Notch2 and TRAP expression levels while lowering those of DLY Notch1, Jagged1, and Hes-1 in osteoporotic rats

RT-qPCR and Western blotting methods were applied in order to detect the mRNA and protein expression levels of LINC00311, DLL3, Notch1, Notch2, Jagged1, and He As illustrated in Fig. 14, compared with those of the sham group, the mRNA and pr expression levels of LINC00311, Notch2 and TRAP in the bone tissues of t JyX $g$ were significantly increased, while the mRNA and protein expression levels of DL Jagged1 and Hes-1 were decreased (all $p<0.05$ ); the TRAP protein expre if len ere significantly increased in the bone tissues of the OVX group $(p<0.05, \quad$ mRN $d$ protein expression levels of LINC00311, Notch2 and TRAP in the bone is a LINC00311 group were increased significantly compared with those $o^{f_{t}}$ OVX reductions in the mRNA and protein expression levels of DLL3, Noto gged1 and Hes-1 were recorded (all $p<0.05$ ). Compared with those of the $C$ roup, th $\mathrm{NA}$ and protein expression levels of LINC00311, Notch2 and TRAP in the roup ignificantly decreased, while the mRNA and protein expression levels o L 3 and Jagged1 were elevated (all $p<0.05$ ). The results suggested that in osteocl c NCu 311 overexpression might increase the Notch2 and TRAP mRNA ex sion levels le lowering those of DLL3, Notch1, Jagged1, and Hes-1.

\section{Discussion}

The prevalence of osteoporosis h ex red progressive increases, with many studies highlighting the demand for more effe ar ement and treatment protocols for patients

Fig. 12. HE staining shows the pat, of bone tissues of osteoporotic HE, hematoxylin-eosin; OVX,
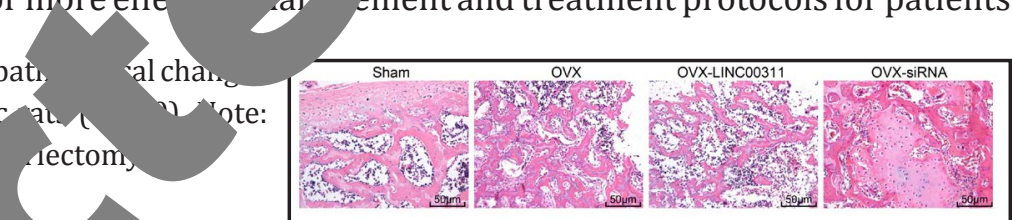

Fig. 13. TRAP mplies that LINC00311 incr as positive osteoclasts in bone tiscues d $\mathrm{ig}$ sporosis $(\times 200)$. Note: $\mathrm{N}=3$ co $\mathrm{n}$ was analyzed using

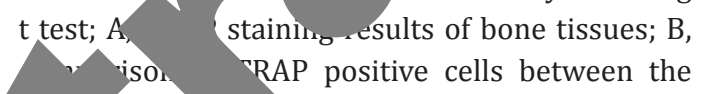
roup a $V X$ groups; ; $\mathrm{p}<0.05$ compared tha roup a
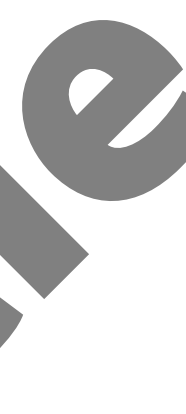

14. $\kappa$ T-qPCR and Western ot analysis demonstrates that
0311 elevates Notch2 and AP expression levels while lowering those of DLL3, Notch1, Notch2, Jagged1, and Hes-1 in $\mathrm{n}$ bone tissues during osteoporosis.

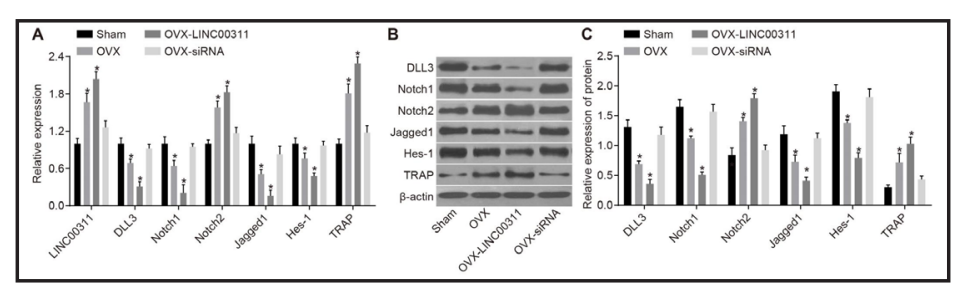

Note: $\mathrm{N}=3$; comparison was

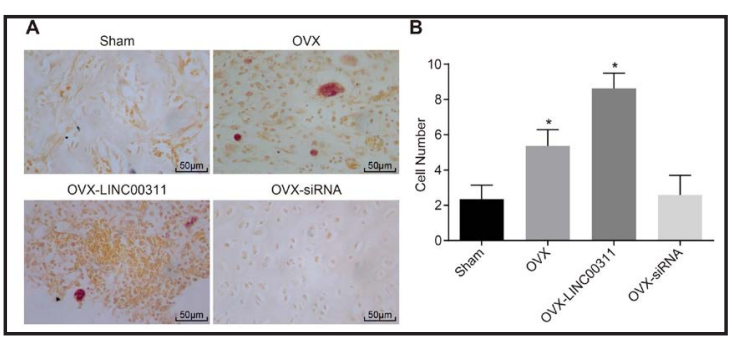

analyzed using an ANOVA; A, mRNA expression levels of relative genes in each group; B, protein bands of relative genes in each group; $\mathrm{C}$, protein expression levels of relative genes in each group; ${ }^{*}, \mathrm{p}<0.05$ compared with the sham group; OVX, ovariectomy; DLL3, delta-like 3; Hes-1, hairy and enhancer of split-1; TRAP, tartrate-resistant acid phosphatase.

\section{KARGER}


suffering from osteoporosis [21]. Largely due to the influence of multiple osteogenetic signals, which are specialized for the proliferation and differentiation of osteoblasts, an increase in the number of osteoblasts results from the mesenchymal progenitor cells [2]. The objective of the current study was to elucidate the correlation between LINC00311 and DLL3 from an osteoporosis perspective. The main conclusion of our study provided verificatir demonstrating that the upregulation of LINC00311 could inhibit the expression of DLL. and regulate the Notch signaling pathway to promote the proliferation and differentiation of osteoblasts.

Compared with that in the sham group, in the OVX group, the expression of IINCO among the osteoclasts was higher, while the expression of DLL3 and the re d gen the Notch signaling pathway was lower. The findings of a recent study regard osa. compensation, imprinting, and homeotic gene expression revealed that vid rge intervening noncoding RNAs (lincRNAs) could function as the interface een $s_{p} c$ chromatin remodeling activities and DNA, suggesting they are pervas ex in the genome [22]. LncRNAs have been employed as biomarkers and th apeut sets in various skeletal diseases including osteoarthritis and osteoporosis, vell as in cancers related to the skeletal system [23], among which the lncB act as a regulatory element in patients suffering from os a of the IncRNA MyoD has been detected in skeletal muscle c an d IncRNA HOTAIR expression has been observed in osteosarcoma tissues [24 JLL is a spondylocostal dysplasia/pudgy gene whose mutation may le? axial skele efects and spondylocostal dysostosis [26-28]. Similarly, DLL3 has been $r_{1}$ to be a didate gene that has been implicated in vertebral malformations, while it ng to Notch represents a significant factor in somitogenesis, capable of promoting teo genesis through Notch2 [29, 30]. A key finding of the present study provided den ggesting that it is reasonable to estimate that LINC00311 is upregulate st and that DLL3 is a factor affecting osteoporosis largely due to the increa at ession levels of a great number of IncRNAs in orthopedic diseases, with many orth dis ses shown to be influenced by DLL3.

Furthermore, we found protein expression levels of Notcru, agged 1 and Hes-1 were significantly increased in the OVX group. In comp sou in the NC and blank groups, the expression levels of DLL3, Notch1, Jagged d Hes-1 e notably decreased in the LINC00311 vector group. Jagged1 is a ligand of $\mathrm{N} \quad 1 \mathrm{an}^{-}$Notch2, and the differential expression levels of the two depend on the thymic ce cions and ontogenetic stages [31, 32]. Osteoclastogenesis is enhanced by 2 /DuL1 axis but suppressed by the Notch1/Jagged1 axis [30]. Hes1 is major tra pathway t is cl al osteoblast differentiation $[33,34]$. Osteoblasts are implicated in the inciden d pro on of osteoporosis [35]. Many lncRNAs are regulated by osteoblasts, i cluding lncRNA repertoire and lncRNA-p21 [36, 37]. DLL3 is an upregulated gene of tch $\mathrm{i}$ ing pathway, which is also regulated by osteoblast activity [15, 38, 39]. addition, when compared with that in the sham group, the ratio of TRAP-positive $n$ the OVX group increased. In comparison to that in the NC and blank groups, the liferauton in the LINC00311-vector group was increased, while the ratio of apoptosis and re rcentage of TRAP-positive osteoclasts decreased. A previous report indicated that Linc TUG1 promotes the proliferation while acting to inhibit the apoptosis of osteosarcoma etls by binding to PRC2 [40]. Linc RNA NONHSAT009968, H19 and HIF $1 \alpha$-anti-sense 1 have been identified to promote osteoblastic differentiation as a result of their potential cisregulated mRNA targeting, which represents a central osteoblast differentiation regulator [41-43]. DLL3 restoration in methylation-silenced HuH2 cells results in the promotion of apoptosis owing to the activity of Huwel, while DLL3 may inhibit proliferation [44, 45]. The upregulation of the Notch signaling pathway may inhibit proliferation while promoting the apoptosis of osteosarcoma cells because doxorubicin treatment mediates a decrease in proliferation and increase in apoptosis of osteosarcoma, effects that are facilitated by that signaling pathway [46].

\section{KARGER}




\section{Cellular Physiology Cell Physiol Biochem 2018;47:2291-2306

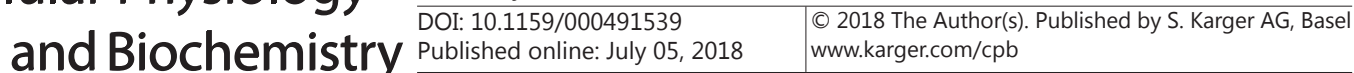 \\ Wang et al.: LINC00311 and DLL3 in Osteoporotic Rats}

In conclusion, the key findings of this study suggest that LINC00311 could well possess the attributes required for osteoclast differentiation via the downregulation of DLL3 and LINC00311. Downregulated DLL3 can promote proliferation and differentiation while inhibiting the apoptosis of osteoclasts by activating the Notch signaling pathway. Therefore, the identification of LINC00311 and the Notch signaling pathway may aid in facilitating $\mathrm{t}^{\mathrm{H}}$ existing understanding of the mechanisms of osteoporosis, with the potential of servin as a prognostic marker for the treatment of osteoporosis in the future. However, due to the sample size and funding limitations, further studies are required to fully underst the specific mechanisms of LINC00311 combined with the Notch signaling-nathw: osteoporosis treatment.

\section{Acknowledgements}

We would like to give our sincere appreciation to the revieye for thelpful comments on this article.

\section{Disclosure Statement}

The authors have declared that no compet interests e.

\section{References}

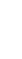

-2 Aggarwal R, Lu J, Kanji S, Joseph M, Das

BS, Rosol TJ, Jackson R, Mao HO Pompil

reverse osteoporosis in NOD

2012;7:e39365.

-3 Management of osteoporo Menopause Society. Mer

$\checkmark 4$ Harvey N, Dennison E, 2010;6:99-105.

$>5$

Watts NB, Di? 2010;95:15

$>6$ Maceyl $\mathrm{Ha}$ m Tre 11 Biol 2:50-60.

\section{inpo use 2010 , -54 ; quiz 55-26.}

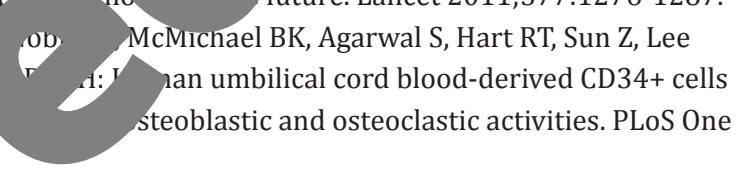
future. Lancet 2011;377:1276-1287.

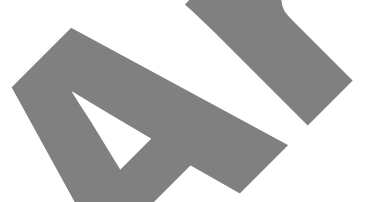

\footnotetext{
7 Zo Lu H, Dai Z, Liu X, Cui L: Expression profiling of IncRNAs in C3H10T1/2 mesenchymal stem clls un gearly osteoblast differentiation. Mol Med Rep 2013;8:463-467.

oller M: won-coding RNAs in human disease. Nat Rev Genet 2011;12:861-874.

a PC, Xu SZ, Lin XJ: Long non-coding RNA-DANCR in human circulating monocytes: a potential

biomarker associated with postmenopausal osteoporosis. Biosci Biotechnol Biochem 2015;79:732-737.
Jang Q, Li Y, Zhang Y, Ma L, Lin L, Meng J, Jiang L, Wang L, Zhou P, Zhang Y: LncRNA MEG3 inhibited osteogenic differentiation of bone marrow mesenchymal stem cells from postmenopausal osteoporosis by targeting miR-133a-3p. Biomed Pharmacother 2017;89:1178-1186.

Vindrios W, Argy N, Le Gal S, Lescure FX, Massias L, Le MP, Wolff M, Yazdanpanah Y, Nevez G, Houze S, Dorent R, Lucet JC: Outbreak of Pneumocystis jirovecii Infection among Heart Transplant Recipients: Molecular Investigation and Management of an Inter-human Transmission. Clin Infect Dis 2017;10.1093/ cid/cix495

12 Penton AL, Leonard LD, Spinner NB: Notch signaling in human development and disease. Semin Cell Dev Biol 2012;23:450-457.
} 


\section{Cellular Physiology Cell Physiol Biochem 2018;47:2291-2306 \begin{tabular}{l|l|l} 
and Biochemistry 10.1159/000491539 & $\begin{array}{l}\text { (c) 2018 The Author(s). Published by S. Karger AG, Basel } \\
\text { www.karger.com/cpb }\end{array}$
\end{tabular} \\ \begin{tabular}{l} 
Published onlIne: July 05, 2018 www.karger.com/cpb \\
\hline Wang et al.: LINC00311 and DLL3 in Osteoporotic Rats
\end{tabular}}

13 Fan JZ, Yang L, Meng GL, Lin YS, Wei BY, Fan J, Hu HM, Liu YW, Chen S, Zhang JK, He QZ, Luo ZJ, Liu J: Estrogen improves the proliferation and differentiation of hBMSCs derived from postmenopausal osteoporosis through notch signaling pathway. Mol Cell Biochem 2014;392:85-93.

14 Sewell W, Sparrow DB, Smith AJ, Gonzalez DM, Rappaport EF, Dunwoodie SL, Kusumi K: Cyclical expression of the Notch/Wnt regulator Nrarp requires modulation by Dll3 in somitogenesis. Dev Biol 2009;329:400409.

15 Wang H, Jiang Z, Zhang J, Xie Z, Wang Y, Yang G: Enhanced osteogenic differentiation of rat bone marrow mesenchymal stem cells on titanium substrates by inhibiting Notch3 Arch Oral Biol 2017;80:34-40 data normalization. BMC Bioinformatics 2006;7:469. Smyth GK: Linear models and empirical bayes methods for assessing differential expression in experiments. Stat Appl Genet Mol Biol 2004;3:Article3.

18 Adler P, Kolde R, Kull M, Tkachenko A, Peterson H, Reimand J, Vilo J: Mining for coexp hundreds of datasets using novel rank aggregation and visualization methods. Genon

19 Wang J, Duncan D, Shi Z, Zhang B: WEB-based GEne SeT AnaLysis Toolkit (WebG^S Nucleic Acids Res 2013;41:W77-83.

20 Wood LD, Parsons DW, Jones S, Lin J, Sjoblom T, Leary RJ, Shen D, B M Marber V, Silliman N, Szabo S, Dezso Z, Ustyanksky V, Nikolskaya T, Nikolsky Y, Karchir N Kamin s, Zhang Z, Croshaw R, Willis J, Dawson D, Shipitsin M, Willson JK, Sukumar S, ak y Pethiyagoda CL, Pant PV, Ballinger DG, Sparks AB, Hartigan J, Smith DR, Suh E, Papad SD, Parmigiani G, Kinzler KW, Velculescu VE, Vogels+ B: The genom colorectal cancers. Science 2007;318:1108-1113.

21 Kanis JA: Diagnosis of osteoporosis and assessment of

22 Gupta RA, Shah N, Wang KC, Kim J, Horlings HM, W Brzoska P, Kong B, Li R, West RB, van de Vijver MJ, reprograms chromatin state to promote cap Huynh NP, Anderson BA, Guilak F, McAlir and disease. Connect Tissue Res 2017;5 regulates skeletal muscle diffe 2015;34:181-191.

25 Wang B, Su Y, Yang Q, Lv RNA HOTAIR Promotes 440.

-27 Bul P, Kus rrayling TM, McKeown C, Garrett C, Lander ES, Krumlauf R, Hattersley AT, Flla rnpenny PD: Mutations in the human delta homologue, DLL3, cause axial skeletal defects in ondy. Jysostosis. Nat Genet 2000;24:438-441.

vnpenny D, Whittock N, Duncan J, Dunwoodie S, Kusumi K, Ellard S: Novel mutations in DLL3, a hesis gene encoding a ligand for the Notch signalling pathway, cause a consistent pattern of abirurnal vertebral segmentation in spondylocostal dysostosis. J Med Genet 2003;40:333-339. Giampietro PF, Raggio CL, Reynolds C, Ghebranious N, Burmester JK, Glurich I, Rasmussen K, McPherson E, Pauli RM, Shukla SK, Merchant S, Jacobsen FS, Faciszewski T, Blank RD: DLL3 as a candidate gene for vertebral malformations. Am J Med Genet A 2006;140:2447-2453.

Sekine C, Koyanagi A, Koyama N, Hozumi K, Chiba S, Yagita H: Differential regulation of osteoclastogenesis by Notch2/Delta-like 1 and Notch1/Jagged1 axes. Arthritis Res Ther 2012;14:R45.

-31 Felli MP, Maroder M, Mitsiadis TA, Campese AF, Bellavia D, Vacca A, Mann RS, Frati L, Lendahl U, Gulino A, Screpanti I: Expression pattern of notch1, 2 and 3 and Jagged 1 and 2 in lymphoid and stromal thymus components: distinct ligand-receptor interactions in intrathymic T cell development. Int Immunol 1999;11:1017-1025. 
